\title{
General Discussion to paper of Dr A. Chantraine et al.
}

\author{
Chairman: PROFESSOR A. RossIER
}

Mr P. HARRIS (G.B.). Mr Chairman, I wonder whether it is possible to spin off of this very interesting paper by Dr Chantraine. Could there be anything in this for some of us who don't understand why para-articular ossification occurs?

DR A. Chantraine (Switzerland). Well I don't think that this study has given us any more information on the paraosteopathy. It is just shown in the long bone in the femur which we have studied particularly.

Mr P. HARris. You also mentioned the change in muscle and the situation of muscles and so on in osteoporosis. I wonder if it would be linked up in any way?

Dr Chantraine. Yes well, osteoporosis yes, but not on the para-osteopathy in this particular study.

CHIKowy (U.S.A.). I have a question for Dr Chantraine. I congratulate you on your paper. Do you find that the changes were the same in a spastic paraplegia versus flaccid paraplegia?

DR ChANTRAIne. I believe all four patients were spastic, so I cannot answer your question.

Dr J. C. Chawla (G.B.). First of all what are the lesions, what are the levels of the lesions of these patients you studied? Because if you are invoking vasomotor control, we must know whether they were above the sympathetic outflow or not, and, secondly, do we know what was the state of their deep veins, and the superficial veins?

Dr Chantraine. The last point is very important and $I$ think it is a very good question. Yes in four patients we had through the study by catheterisation we had done four patients had a profound femoral vein occluded and it must play a role as Brooks and Shim have shown previously. Now on the first slide which was very heavy the level of each patient is given which you can see in the paper.

DR G. S. BRINDLEY (G.B.). In the hemiplegic patient did you do the venous pressure measurements on the hemiplegic side and the normal side and were they different if so?

Dr Chantraine. Yes. We have investigated both sides at the same time and we have at the same time taken a piece of bone, a biopsy of the iliac crest, to measure the differences which exist. So there is the paralysed side which has osteoporosis and normal side which is normal, and we have seen also on the study of intramedullary pressure that the pressure was elevated in the paralysed side while in the normal side it was normal.

PRof. A. Rossier. It seems to me that this study points to a very basic thing for me which was what Dr Harris was asking although the authors have not in this case focussed the study on POA ectopic bone ossification. But it has proven something that it seems that what you have shown is related to the sympathetic nervous system which points again to some aetiology of factors proposed for the formation of ectopic bone ossification. So I think you have moved one step further in this direction for me, indirectly.

CHIkowy (U.S.A.). I don't think that that's the case. Similar findings have been seen in just idiopathic osteoporosis as you mentioned before so I don't see that the central nervous system had to be involved here.

DR ChANTRAINE. Well I gave last year a paper on the actual concept of osteoporosis in paraplegia and I don't think that immobilisation has anything to do with osteoporosis.

DR Chawla (G.B.). Now we are in business. I do not think you can invoke sympathetic changes at all in this paper, because you have not shown us any evidence of this because you have shown the similar changes in the hemiplegic bone.

Dr CHANTRAINE. Well in the hemiplegic paralysed side there is also a sympathetic alteration. You know the different centres in the spinal cord of the sympathetic system are under the centre in the hypothalamus.

Dr Chawla (G.B.). That is true, it is the centre but on the other hand you definitely 
exclude that there is no deep venous thrombosis. There is no occlusion to the veins because there has to be venous drainage, and you have shown in four cases that there is a venous obstruction.

Dr Chantraine. In four patients we had venous obstruction but in the other patients we had no obstruction.

Dr. Chawla (G.B.). Furthermore the sympathetic does not play a very important role in the venous drainage, it's got more effect on the arterial flow.

DR Chantraine. Anyway there is a vasomotor paralysis.

DR P. Dollfus (France). I would make a little suggestion. Could you try this experiments on patients in coma? Why not do it in people who have brainstem lesions or coma?

Dr Chantraine. There is a good reason in these two states. You cannot ask for their consent.

PROF. Sussmann (U.S.A.). I wonder if possibly you could try this study together with the earlier one on Marcaine Epidural Anaesthesia which is still bugging me. It would be an interesting experiment to see if the vasomotor changes which you have demonstrated as a result of cord lesion could be interfered with by duplication of the earlier experiment by which following the cord injury by a blockade effect in the epidural space.

Dr Chantraine. I'm sorry I don't quite understand what you mean.

Prof. Sussmann. You say this is a vasomotor effect, presumably of a sympathetic origin, if so an extradural sympathetic blockade with Marcaine as it was done in the earlier study is easy to accomplish. This would get at two important facts, one it would give us some idea of the mechanism of the earlier study and I think it would prove whether your results are in fact of sympathetic origin.

Dr Chantraine. Well Shim and Brooks have already done that on cats and dogs. They cut the sympathetic nerve and the sciatic nerve and they have in the femoral bone the increase of the intramedullary pressure. I mentioned the paper.

Prof. Rossier. Any other questions? If not, I think we are 50 minutes ahead. Thank you for your comments and your help. 